\title{
PRESENTACIÓN: EL ESTUDIO DE LA AUTORIDAD COMO TAREA ACTUAL
}

\author{
Kathya Araujo ${ }^{1}$
}

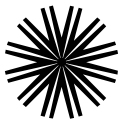

La autoridad es un tema de central importancia en las ciencias sociales. Lo es porque toca el corazón mismo de la comprensión de una sociedad. La autoridad es un fenómeno que está en acción en situaciones tan disímiles como cuando alguien no bebe al conducir porque una ley lo prohíbe; cuando se intenta producir un ambiente de tranquilidad en un grupo alterado; cuando se está en una sala de clase dictando una materia; cuando se trata de expandir una opinión o una postura en un grupo o sociedad; o cuando lo que está en juego es la salida de un adolescente a una fiesta nocturna. Ninguna sociedad puede subsistir, en rigor, sin algún modo de influencia posible en la conducta o ideas de otros, lo que implica un ejercicio de poder sobre ellos, que es lo mismo que decir que ninguna sociedad puede subsistir sin autoridad, No puede porque, como lo ha señalado, entre otros, un autor tan temprano y tan poco sospechoso de alentar la dominación como Friedrich Engels (1941), no hay organización sin autoridad. Toda organización social supone coordinación y la coordinación supone subordinación de una voluntad respecto a la otra. Pero, todavía más, la autoridad resulta nuclear puesto que este fenómeno es el que permite explicar que una orden, una norma o una influencia en la dirección de la conducta no se impongan por la mera fuerza bruta. La autoridad da lugar a manifestaciones de obediencia no directa o explícitamente forzadas, que son constituyentes de la vida social (Weber 1964, Arendt 1996, Kojève 2005).

Sin embargo, la autoridad como fenómeno en sí no ha recibido la atención que debería. En efecto, es un topos extendido en las ciencias sociales el desfase enorme entre la centralidad del fenómeno de la autoridad para entender la vida social y el reducido, comparativamente, número de trabajos que la abordan de manera directa. Nos referimos, por cierto, a trabajos que hagan de este fenómeno su centro analítico. La autoridad en cuanto asociada al problema del poder está tocada de manera indirecta, y muchas veces inadvertida o solo

1 Universidad Academia de Humanismo Cristiano. E-mail: karaujok@docentes.academia.cl 
implícitamente, en una cantidad muy importante de trabajos. Esto es así porque en la vida social ellos están íntimamente ligados aunque deben ser claramente distinguidos: la autoridad no es el ejercicio de poder per se sino el fenómeno que permite un cierto tipo de ejercicio de poder. Es este foco particular y diferenciado el que ha resultado particularmente escaso en los abordajes. Es así que no cesamos de hablar implícitamente de autoridad, no dejamos de toparnos con sus efectos o la falta de ellos, y sin embargo...

Tiene algo de escandaloso este descuido, sin duda, pero, no es del todo incomprensible. Por dos razones por lo menos. Por un lado, lo que explica esta brecha es una combinación de los efectos de la trayectoria histórica del concepto y los destinos políticos que lo alcanzan (que retraen la temática a un segundo plano), y por el otro, qué duda cabe, la complejidad que el propio fenómeno plantea teóricamente.

En efecto, la autoridad es un tema fuertemente asociado con dimensiones valóricas y políticas. Ya en el siglo XIX europeo, la autoridad es objeto de discordia: asociada con las posiciones que Nisbet, en su tipología, ha llamado conservadoras (1996), fue objeto de una defensa cerrada en un momento en que los arrestos de la Ilustración proponen, como lo ha formulado Gadamer, "la sumisión de toda autoridad a la razón" (1997: 346), mientras que, del otro lado, los arrestos revolucionarios apuntan a desvirtuarla completamente. Esta disputa política y moral no dejará de estar presente en el siglo que le sigue y hasta nuestros días.

Aunque los clásicos de la sociología, en la vuelta e inicios del siglo XX, de Weber (1964) a Simmel (1986) pasando por Durkheim (2002), y a pesar de sus diferencias, van a subrayar su papel como garantía para la estabilidad de todo orden social, lo que la hace no solo inevitable sino incluso, como en el caso de Durkheim, fundamental y deseable, la autoridad de manera parcial pero certera irá perdiendo a lo largo del siglo XX sus cartas de nobleza. Fenómenos como el fascismo alemán y sus devastadoras consecuencias generarán que la autoridad, y su contracara la obediencia, sean puestas radicalmente en cuestión y colocadas bajo sospecha. Clara expresión de lo anterior es el desplazamiento del interés por la autoridad al autoritarismo presente en las reflexiones de los representantes de la Escuela de Frankfurt, como motivación analítica (Adorno et al, 1965), pero, también, y adicionalmente, como fuente de inspiración política (Marcuse 1993). Pero, también, la pregunta inquietante por la obediencia que abrirá en este contexto Arendt (1966: 285-298) a partir de su análisis del caso Eichmann, y que seguirán otros, entre los cuales de manera 
destacada Milgram (1980) quien buscará revelar los resortes de una ordinaria tendencia a la obediencia ciega.

Los movimientos contraculturales que avanzan en los años sesenta, por su parte, van a aportar a la crítica radical de la autoridad (Cueva, 2007), cargarla negativamente y producir un desplazamiento en el que el problema de la autoridad será subsumido por el del poder y la dominación. Si las discusiones sobre el poder y su capacidad de moldear nuestros actos no disminuyeron sino que ganaron cada vez más importancia, como lo revela el trabajo de Althusser (1992), Castoriadis (1975), Butler (1997), o la obra de Michel Foucault, las formas de conceptualizarlo, en general, o bien no se detuvieron de manera especial en el fenómeno de la autoridad en sí, o bien, cuando lo hicieron, no la llamaron más por su nombre (Bourdieu, 2000). La consecuencia de estos movimientos es, sin sorpresa, que los análisis detenidos del concepto desde las ciencias sociales no hayan resultado demasiado frecuentes.

Pero junto a razones de tipo histórico-políticas, también se encuentran razones teóricas que explican la relativa escasa atención dada a la temática de la autoridad. Para muchos autores, el limitado abordaje del tema se explica por la dificultad que éste encierra para su estudio (Revault D’Allonnes 2008). No hay duda sobre lo anterior. No la hay, porque es y ha sido un desafío tanto teórico como para la investigación empírica aprehender este fenómeno, y ello por al menos tres razones. La primera, porque la noción de autoridad no es unívoca y refiere a diferentes dimensiones, cuya discriminación no ha resultado sencilla y su articulación compleja. Las aristas del fenómeno son diversas (su fundamento, su ejercicio o la obediencia), lo que ha hecho difícil alcanzar una mirada de conjunto del mismo. La segunda, debido a la dificultad para aprehender "el lado oscuro" que comporta. Esa dimensión inexplicable que hace que se otorgue espontáneamente autoridad a una persona y a otra no. Esa fuerza oscura que sostiene nuestra fascinación y nuestra disposición a someter nuestros actos a la voluntad de otro, bien señalada por diversos y muy diferentes autores (Freud 1973, Zizek 2001, Ricoeur 2001). Pero, no solo por ello, también, y en tercer lugar, porque el despliegue de la autoridad ha tendido a ser concebido de manera mucho más compacta de lo que el fenómeno realmente admite. Este punto de partida ha conducido a la obliteración de las formas particulares que éste toma en diferentes realidades socio-históricas, grupos sociales e incluso ámbitos sociales y, como efecto, ha llevado a traslapes, distorsiones o ha fornecido a la discusión de premisas falsas. Haber desatendido la multiplicidad del fenómeno no solo ha oscurecido la discusión teórica sino 
que, todavía más, y de forma importante, ha lastrado el abordaje empírico del fenómeno.

Esta situación exige ser transformada. No solo por cuestiones disciplinarias, sino porque el momento histórico en el que nos encontramos lo demanda. Por supuesto no en virtud de una supuesta crisis de la autoridad que aconsejaría volver a las formas tradicionales. Esta exigencia proviene, más bien, del hecho que lo que encaran las sociedades ha adquirido una cierta direccionalidad reconocible: un conjunto de procesos de tipo normativo, materiales e institucionales que empujan a la transformación de los modos de regulación de las relaciones sociales, entre los cuales la gestión de las jerarquías, centro mismo del campo de acción de la autoridad, no es en modo alguno el menor.

Nuestra historia occidental en los últimos siglos ha estado caracterizada por transformaciones estructurales que han modificado de manera importante el rostro de la vida social. No solo se han transformado las bases materiales sino que también, han entrado en circulación, de manera contradictoria y agonística, es verdad, nuevos principios y modelos de sociedad que han puesto en cuestión formas convencionalmente aceptadas de concebir las relaciones sociales y los principios de autoridad que rigen las interacciones. Existen síntomas en todas partes que hacen pensar que el cuestionamiento de la jerarquía ha tenido desarrollos importantes, obligando a una recomposición de las formas de su gestión. Las dudas sobre la democracia representativa y los empujes hacia modelos de democracia participativos. Las nuevas exigencias que ponen los estudiantes a sus maestros para el establecimiento de sus relaciones. El incremento de formas descentradas y horizontales en la acción política. Pero, también, y solo para mencionar algunos, la brutalidad coercitiva que adquieren las relaciones laborales precisamente como contracara y respuesta a este fenómeno de cuestionamiento a la jerarquía.

Del lado luz y del lado sombra, lo acontecido revela de la premura y hasta urgencia que reviste revisar las maneras en que las sociedades resuelven esta cuestión. Desde esta perspectiva, la doble actualidad, intelectual y social, del estudio de la autoridad se impone. Es una exigencia central renovar su estudio porque la autoridad no es sino una vía, la privilegiada, para lidiar con las asimetrías constitutivas de lo social de manera de hacer posible la vida social misma. Acometer esta tarea implica alcanzar no solo un diagnóstico ajustado 
y situado de lo que se enfrenta, sino, también, volver a interrogar teóricamente la propia noción de autoridad.

Este dossier tiene como objetivo, con sus alcances y sus límites, contribuir a este debate. Los textos incluidos en él y sus aportes son de distinta naturaleza. Por un lado, de diferentes maneras y con intensidades distintas, salen de una lectura que hace eco de la oposición excluyente que ha estructurado el debate valórico y político que la acompaña. Recogen la noción que la autoridad es, como ya lo sabían los clásicos, al mismo tiempo que instrumento posible de la dominación, una garantía para la estabilidad social y, también, no hay que olvidarlo, de la integridad personal. Una ambivalencia, con todas sus consecuencias, que requiere ser considerada como la brújula más segura en este camino. Por otro lado, buena parte de los mismos hacen la apuesta de enfrentar esta cuestión a partir del desarrollo de estudios empíricos, los que además están, en buena medida, caracterizados por una fuerte sensibilidad acerca de la naturaleza múltiple y situada del despliegue de la autoridad. Finalmente, estos trabajos exhiben un genuino interés por, y en algunos casos una sustantiva contribución a, una reflexión teórica renovada del problema de la autoridad.

Las contribuciones de Guillermo Nugent y Danilo Martuccelli abordan la cuestión teórica de cómo pensar la autoridad en las sociedades actuales. Martuccelli subraya y discute, sacando las consecuencias para la crítica social, la expansión de una autoridad factual, sostenida en la "fuerza misma de las cosas", la que reemplazaría la hegemonía de una autoridad relacional. Con acuciosidad el autor presenta los fenómenos que revelan cómo, en el ámbito de la autoridad, las cuestiones de la ideología o la legitimidad dejarían su lugar a la de las coerciones reales e impersonales. Nugent, por su parte, se centra en el problema de la eficacia moral en sociedades, como la peruana, y latinoamericanas, caracterizadas por lo que ha llamado el orden tutelar. Los siguientes textos se abocan al estudio de la autoridad en ámbitos específicos y basados en investigaciones empíricas. Pablo Neut y Paula Subiabre la estudian en el contexto de la educación escolar. Neut, basado en un estudio en establecimientos que reciben a jóvenes vulnerables, centra su atención en los modos en que las transformaciones sufridas en las últimas décadas por la sociedad chilena han puesto en cuestión a la autoridad pedagógica así como, de manera destacada, de las modalidades en que ella se recrea hoy. Subiabre en un espíritu similar, pero en una perspectiva histórica, analiza los avatares que sufre la autoridad del profesor entre 1973 y 2010 a partir de un estudio de caso, el Instituto Nacional, probablemente la institución escolar pública de mayor prestigio en el país, enhebrando los procesos macros con las transformaciones 
institucionales y los caminos que toman las relaciones de autoridad concretas. En otro ámbito, Paula Contreras, discute la relación entre el relato cultural del autoritarismo dictatorial y los miedos sociales. Basada en los resultados de un estudio realizado en Santiago, tanto en sectores populares como medios, la autora especifica las aristas que componen este relato cultural, y presenta con detalle la manera en que éste participa en conformar los rasgos de los miedos sociales. La pregunta que el texto de Mariana Valenzuela busca responder se sitúa en el campo de la producción de legitimidad de las figuras políticas. Analiza las formas de presentación de Michelle Bachelet y Cristina Kirchner, a través del análisis de discursos y entrevistas, para discutir la manera en que el género se convierte, aunque en modalidades distintas, en una herramienta de legitimación en ambos casos. Finalmente, el artículo de Claudia Pérez, basada en el caso de las cadetes de la Escuela Militar de Chile, busca poner en evidencia la importancia del factor temporal para entender el fenómeno de la autoridad así como sacar las consecuencias de su naturaleza variable en tanto relación social y producto social colectivo.

Para terminar, solo queda decir que esperamos que este conjunto de trabajos no solo permita continuar abriendo las conversaciones sobre la autoridad en nuestra comunidad científica, sino que, de manera todavía más importante, éste consigan estimular el interés de nuevos investigadores por este campo. 
Referencias bibliográficas

Adorno, T. et al. (1965). La personalidad autoritaria. Buenos Aires: Proyección.

Althusser, L. (1992). Ideología y aparatos ideológicos del Estado. Argentina: Editorial Nueva Visión.

A rendt, H. (1996). Entre el pasado y el futuro, ocho ejercicios sobre la reflexión politica. [1968] Madrid: Península.

Arendt, H. (1966). Eichmann in Jerusalem: a report on the banality of evil. New York: Viking Press.

Bourdieu, P. (2000). Sobre el poder simbólico. En Intelectuales, politica y poder. Buenos Aires: UBA/EUDEA. pp 65 - 73.

Butler, J. (1997). Mecanismos Psíquicos del Poder. Madrid: Editorial Cátedra. Castoriadis, C. (1975). La Institución imaginaria de la sociedad. Barcelona: Editorial Tusquets.

Cueva, M. (2007). De la gran liberación al fin de la autoridad. Revista Mexicana de Sociologia. (69)2 (abril-junio), pp, 243 - 275.

Durkheim, E. (2002). La Educación Moral [1947]. Madrid: Trotta.

Engels, F. (1941). Sobre el Anarquismo. Madrid: Editorial Proyecto Espartaco.

Freud, S. (1973). Psicología de las masas y análisis del yo, en Obras Completas, t-3. Madrid: Biblioteca Nueva.

Gadamer, H.G. (1997). Verdad y Método. Salamanca: Ediciones Sígueme.

Kojève, A. (2005). La noción de autoridad. Argentina: Nueva visión.

Marcuse, H. (1993). El hombre unidimensional. Buenos Aires: Editorial Planeta.

Milgram, S. (1980). Obediencia a la autoridad. Bilbao: Desclée de Brouwer. 
Nisbet, R. (1996). La formación del pensamiento sociológico 1. Buenos Aires: Amorrortu.

Revault D’ Allonnes. M. (2008). El poder de los comienzos. Ensayo sobre la autoridad. Buenos Aires: Amorrortu.

Ricoeur, P. (2001). Les catégories fondamentales de la sociologie de Max Weber. En P. Ricoeur. Le juste 2, Paris: Spirit., pp, $155-71$.

Simmel, G. (1986). Sociología I. Estudios sobre las formas de socialización. Madrid: Alianza editorial.

Tocqueville, A. (1961), De la démocratie en Amérique. Paris, Gallimard, 2 vols.

Weber, M. (1964). Economia y Sociedad. México: FCE.

Zizek, S. (2001). El espinoso sujeto [1999]. Buenos Aires: Paidós. 